\title{
A capacitação de servidores do IFRS sob a perspectiva da Política Nacional de Desenvolvimento de Pessoal - PNDP
}

\author{
Ângela Marin \\ Instituto Federal do Rio Grande do Sul (IFRS) Sul \\ (angela.marin@ifrs.edu.br) \\ Aline Grunewald Nichele \\ Instituto Federal do Rio Grande do Sul (IFRS) Sul - Campus Porto Alegre \\ (aline.nichele@poa.ifrs.edu.br)
}

\begin{abstract}
Resumo: O presente artigo apresenta um recorte de uma pesquisa que tem como tema central a capacitação de servidores do Instituto Federal de Educação, Ciência e Tecnologia do Rio Grande do Sul (IFRS) numa perspectiva de formação integral e à luz dos preceitos da Educação Profissional e Tecnológica. A pesquisa referida está vinculada ao Mestrado Profissional em Educação Profissional e Tecnológica - ProfEPT, do Campus Porto Alegre do IFRS. No âmbito do IFRS, lócus da pesquisa, a capacitação de servidores é um tema estratégico para a garantia da oferta de Educação Profissional e Tecnológica (EPT) voltada para a formação integral de cidadãos, estando prevista no Plano de Desenvolvimento Institucional (PDI). Recentemente o Decreto $\mathrm{n}^{\circ} 5.707 / 2006$, foi revogado pelo Decreto $n^{\circ} 9.991 / 2019$, provocando diversas alterações na condução das ações de capacitação na esfera federal. Desta forma, o presente artigo visa à análise do que era preconizado pelo Decreto $\mathrm{n}^{\circ}$ 5.707/2006, traçando-se um paralelo com o Programa de Capacitação dos Servidores do IFRS (Resolução Consup IFRS no 114/2014), cuja finalidade é servir de base para um estudo posterior sobre os impactos do Decreto $n^{\circ} 9.991 / 2019$ nas ações e políticas de capacitação dos servidores da instituição. A abordagem metodológica adotada é a pesquisa qualitativa, de natureza aplicada, do tipo exploratória, em que os dados foram produzidos por meio de pesquisa bibliográfica e documental, tendo como principal fonte de dados os decretos anteriormente citados e suas regulamentações, bem como o Programa de Capacitação dos Servidores do IFRS. Percebeu-se que o referido programa acompanha ao preconizado pelo então revogado Decreto $n^{\circ} 5.707 / 2006$, sendo possível antever o primeiro impacto do Decreto $\mathrm{n}^{\circ} 9.991 / 2019$, que é a revisão das normativas internas do IFRS que versam sobre o tema capacitação de servidores. Alerta-se, contudo, que ao revisá-las, tenha-se como horizonte a formação integral dos servidores da instituição.
\end{abstract}

Palavras-chave: Capacitação de Servidores Federais; Política Nacional de Desenvolvimento de Pessoal; IFRS.

\section{The professional qualification of the IFRS civil servants under the perspective of the National Policy of Staff Development - PNDP}

Abstract: This paper is part of a research that has as central theme the professional qualification of the civil servants from the Federal Institute of Education, Science and Technology of Rio Grande do Sul (IFRS) from the perspective of integral formation and in the light of the precepts of Vocational and Technological Education. The aforementioned research is linked to the Professional Master's in Vocational and Technological Education - ProfEPT from Campus Porto Alegre of IFRS. Within the IFRS, the locus of research, the qualification of civil servants is a strategic subject to ensure the offering of vocational and technological education (EPT) devoted to the integral formation of citizens, as stated in the Institutional Development Plan (PDI). Recently, the Decree no. 5707/2006 was repealed by Decree no. 9991/2019, causing several changes in the conduction of training actions in the federal sphere. Thus, this paper aims for the analysis of what was recommended by the Decree no. 5707/2006, drawing a parallel with the IFRS Civil Servants Qualification Program (Consup IFRS Resolution no. 114/2014), that has as its purpose to serve as a basis for further studies about the impact of Decree No. 9991/2019 on the qualification actions and policies of the institution servants. The methodological approach adopted is qualitative research of applied nature and of exploratory 
kind, in which data was produced through a bibliographic and documental research, having as its main source of data the decrees and regulations aforementioned, as well as the IFRS Civil Servants Qualification Program. It was noticed that the program follows what was recommended by the then repealed Decree No. 5707/2006, making it possible to foresee the first impact of Decree No. $9.991 / 2019$, which is the revision of the IFRS internal regulations that focus on the civil servants qualification. Nevertheless, it is worthy of note that while such regulations are being revised, the integral formation of the civil servants of the institution should be kept in mind.

Keywords: Professional Qualification of Federal Civil Servants; National Policy of Staff Development; IFRS.

\section{INTRODUÇÃO}

A Rede Federal de Educação Profissional, Científica e Tecnológica é composta pela Universidade Tecnológica Federal do Paraná (UTFPR), pelos Centros Federais de Educação Tecnológica Celso Suckow da Fonseca - (CEFET$\mathrm{RJ}$ ) e de Minas Gerais (CEFET-MG), pelas Escolas Técnicas Vinculadas às Universidades Federais, pelo Colégio Pedro II e pelos Institutos Federais de Educação, Ciência e Tecnologia, totalizando 38 instituições, espalhadas em todos os Estados do Brasil (BRASIL, 2008).

Os Institutos Federais, que compõem a Rede Federal, foram criados através da Lei $n^{\circ}$ 11.892, de 29 de dezembro de 2008. São instituições pluricurriculares e multicampi, que ofertam educação básica e superior e estão compromissados com a justiça social, a equidade, a competitividade econômica e a geração de novas tecnologias e "com o estreito compromisso com o desenvolvimento integral do cidadão trabalhador" (BRASIL, 2010, p. 3).

Dentre essas 38 instituições que compõe a Rede Federal está o Instituto Federal de Educação Ciência e Tecnologia do Rio Grande do Sul - IFRS, lócus da presente pesquisa.

O IFRS é considerado uma autarquia federal, vinculada ao Ministério da Educação (MEC), que tem por finalidade ofertar Educação Profissional e Tecnológica (EPT), em todos os seus níveis e modalidades. Está equiparado às universidades federais no que diz respeito a regulação, avaliação e supervisão da instituição e dos cursos de educação superior (BRASIL, 2008).

A Reitoria do IFRS localiza-se na cidade de Bento Gonçalves, e a instituição possui 17 campi: Alvorada, Bento Gonçalves, Canoas, Caxias do Sul, Erechim, 
Farroupilha, Feliz, Ibirubá, Osório, Porto Alegre, Restinga (Porto Alegre), Rio Grande, Rolante, Sertão, Vacaria, Viamão e Campus Avançado Veranópolis.

O IFRS oferta mais de 250 opções de cursos técnicos e superiores de diferentes modalidades, atendendo cerca de 20 mil alunos (IFRS, 2018a). De acordo com a Plataforma Nilo Peçanha ${ }^{1}$ (PNP), em 2018, a instituição contava em seu quadro com aproximadamente 2000 servidores, distribuídos nas carreiras docente e técnico-administrativos em educação (BRASIL, 2019a).

A instituição considera que "todos os trabalhadores envolvidos nos processos e atos educativos são considerados trabalhadores da educação" (IFRS, 2018b, p. 34), que contribuem, de forma direta ou indireta, para os processos de ensino e de aprendizagem em EPT.

O IFRS tem como missão

Ofertar Educação Profissional, Científica e Tecnológica, inclusiva, pública, gratuita e de qualidade, promovendo a formação integral de cidadãos para enfrentar e superar desigualdades sociais, econômicas, culturais e ambientais, garantindo a indissociabilidade entre ensino, pesquisa e extensão e em consonância com potencialidades e vocações territoriais. (IFRS, 2018b, p. 39).

Para concretizar esta missão e garantir a qualidade da educação ofertada pelo IFRS, faz-se necessário o investimento em ações de capacitação ou formação continuada - entendidas como sinônimos nesse trabalho - que proporcionem aos seus servidores os conhecimentos necessários ao desenvolvimento de suas atividades, o entendimento de seu papel perante a instituição da qual faz parte, bem como perante a sociedade.

O objetivo estratégico de capacitar os servidores da instituição está expresso no Plano de Desenvolvimento Institucional (PDI). O documento dita que o IFRS deve criar oportunidades para que seus trabalhadores em educação possam qualificar-se através da participação em ações de formação continuada e, quando possível, deve arcar com as despesas decorrentes dessa formação, além de estabelecer uma série de metas para a capacitação tanto de docentes como de técnico-administrativos em educação (IFRS, 2018b).

\footnotetext{
${ }^{1}$ A plataforma Nilo Peçanha (PNP) é uma Plataforma estatística do Ministério da Educação para análise de dados e indicadores da Rede Federal de Educação Profissional, Cientifica e Tecnológica do Brasil. Está disponível para acesso e consultas em: http://plataformanilopecanha.mec.gov.br/ 
Enquanto autarquia federal vinculada ao MEC, o IFRS subordina-se a uma série de regramentos (leis, decretos e outros atos normativos) que regulamentam sua atuação, entre elas, às que referem a capacitação de servidores.

Nesse sentido, o IFRS, quanto à formação de seus formadores, deve observar os preceitos da Política Nacional de Desenvolvimento de Pessoas (PNDP), (re)instituída recentemente pelo Decreto Presidencial $n^{\circ}$ 9.991, de 28 de agosto de 2019 e regulamentada pela Instrução Normativa (IN) $n^{\circ} 201$, de 11 de setembro de 2019, editada pela Secretaria de Gestão e Desempenho de Pessoal (SGDP) do Ministério da Economia (ME). Este decreto revogou o Decreto Presidencial $\mathrm{n}^{\circ}$ 5.707/2006, de 23 de fevereiro de 2006 que versava sobre a mesma matéria.

Esse novo decreto, tal qual o anterior, orienta para o desenvolvimento de competências nos servidores do Poder Executivo Federal. Enquanto o Decreto 5.707/2006 preconizava a "melhoria da eficiência, eficácia e qualidade dos serviços públicos prestados ao cidadão", através do "desenvolvimento de conhecimentos, habilidades e atitudes necessárias ao desempenho das funções dos servidores, visando ao alcance dos objetivos das instituições" (BRASIL, 2006a); o Decreto 9.991/2008 orienta para o "desenvolvimento dos servidores públicos nas competências necessárias à consecução da excelência na atuação dos órgãos e das entidades" da administração pública federal, a fim de garantir a "consecução de seus objetivos institucionais". Este último decreto entende por competência o "conjunto de conhecimentos, habilidades e condutas necessários ao exercício do cargo e função" (BRASIL, 2019b).

Percebe-se uma similaridade conceitual muito grande entre estes dois decretos, a "inovação" do Decreto 9.991/2019 está numa série de alterações em ações de capacitação - que ele conceitua como ações de desenvolvimento - tais como nos afastamentos dos servidores, na licença capacitação e na forma como se dará o planejamento dessas ações de desenvolvimento, o que causará impacto na forma como o IFRS conduz sua política de capacitação de servidores.

Considerando este cenário, o objetivo do presente artigo é relatar o que preconizava o Decreto $\mathrm{n}^{\circ} 5.707 / 2006$ e os reflexos deste no Programa de Capacitação de Servidores do IFRS, aprovado pela Resolução do Conselho Superior (CONSUP) $n^{\circ} 114 / 2014$, para, em estudo posterior, analisar os impactos do novo Decreto $n^{\circ}$ 9.991/2016 para as ações de capacitação do IFRS. 
Cabe destacar também que o presente artigo é o recorte do referencial teórico construído em uma pesquisa aplicada, qualitativa, do tipo exploratória que proporcionará elaboração de um material textual do tipo guia, a ser desenvolvido no âmbito do Programa de Mestrado Profissional em Educação Profissional e Tecnológica (ProfEPT), vinculado à área de Ensino da CAPES, ofertado no Instituto Federal de Educação, Ciência e Tecnologia do Rio Grande do Sul (IFRS), que tem como tema central a capacitação de servidores numa perspectiva de formação integral, à luz dos preceitos da Educação Profissional e Tecnológica (EPT).

\section{MATERIAIS E MÉTODOS}

Para a construção do presente artigo tomou-se como base os resultados parciais da pesquisa de mestrado citada anteriormente, oriundos da análise documental realizada em: a) normativas de abrangência nacional, especificamente, o Decreto $n^{\circ}$ 5.707/2006, a Portaria $n^{\circ} 208$, de 25 de julho de 2006 editada pelo então Ministério do Planejamento, Orçamento e Gestão ${ }^{2}$ (MPOG), Decreto $\mathrm{n}^{\circ}$ 9.991/2019 e IN SGDP/ME n 201/2019; b) normativas internas do IFRS, em especial o Programa de Capacitação dos Servidores do IFRS (Resolução Consup IFRS 114/2014). Desta forma, em termos de metodologia, a presente pesquisa pode ser classificada como: aplicada, qualitativa, do tipo exploratória, sendo a pesquisa documental a principal fonte de produção de dados.

É considerada aplicada, pois, conforme Silveira e Córdova (2009, p. 35), "objetiva gerar conhecimentos para a aplicação prática, dirigidos à solução de problemas específicos", o que neste contexto, significa dizer que a análise do que preconizava a antiga PNDP (Decreto $n^{\circ} 5.707 / 2006$ ) servirá de base para o estudo posterior dos impactos da nova PNDP (Decreto $n^{\circ}$ 9.991/2019) nas ações de capacitação do IFRS.

Trata-se também de pesquisa qualitativa, pois preocupa-se com o aprofundamento da compreensão de aspectos de uma organização (SILVEIRA; CÓRDOVA, 2009). Para Minayo (2001, apud SILVEIRA; CÓRDOVA, 2009, p. 32), a

\footnotetext{
${ }^{2}$ Atualmente Ministério da Economia. Em consulta ao site http://www.planejamento.gov.br/ (acesso em 27 de jun. 2019), verificou-se que a partir de 01/01/2019, com a Medida Provisória n. 870/2019 "as estruturas dos ministérios da Fazenda; do Planejamento, Desenvolvimento e Gestão; da Indústria, Comércio Exterior e Serviços; e do Trabalho passaram a integrar um novo ministério chamado Economia".
} 
pesquisa qualitativa "trabalha com o universo de significados, motivos, aspirações, crenças, valores e atitudes, o que corresponde a um espaço mais profundo das relações, dos processos e dos fenômenos". No mesmo sentido, Negrine (2010, p. 62) destaca que "a pesquisa qualitativa tem como pressuposto científico manipular informações recolhidas, descrevendo e analisando-as, para num segundo momento interpretar e discutir à luz da teoria".

Também pode ser classificada com exploratória, pois tem por objetivo "proporcionar maior familiaridade com o problema, com vistas a torná-lo mais explícito" (GIL, 2002, p. 41).

Com relação à produção dos dados, a pesquisa além de bibliográfica, será documental, visto que se dará a partir da consulta a documentos oficiais, mais especificamente legislação de âmbito federal e normativas internas no âmbito do IFRS. O que está em conformidade com o que aponta Fonseca (2002, p. 32, apud SILVEIRA; CÓRDOVA, 2009, p. 37) que diz que a pesquisa documental pode ocorrer em fontes diversificadas "tais como: tabelas estatísticas, jornais, revistas, relatórios, documentos oficiais, cartas, filmes, fotografias, pinturas, tapeçarias, relatórios de empresas, vídeos de programas de televisão, etc".

\section{RESULTADOS E DISCUSSÃO}

O Decreto 9.991/2019, que dispõe sobre a nova Política Nacional de Desenvolvimento de Pessoal (PNDP) em vigor a partir de 06 de setembro de 2019, revogou o Decreto 5.707/2006 e trouxe uma série de alterações para o planejamento de ações de desenvolvimento (até então denominadas ações de capacitação), para os afastamentos para participação em ações de aperfeiçoamento profissional (treinamento regularmente instituído e estudo no exterior) e ações de educação formal (permite apenas afastamentos para pós-graduação stricto sensu), bem como a licença para capacitação. Esse novo decreto tem por finalidade "promover o desenvolvimento dos servidores públicos nas competências necessárias à consecução da excelência na atuação dos órgãos e das entidades da administração

pública federal direta, autárquica e fundacional" tendo como horizonte o desenvolvimento de ações "necessárias à consecução de seus objetivos institucionais" (BRASIL, 2019b). 
A PNDP instituída pelo revogado Decreto $n^{\circ} 5.707 / 2006$, trazia em seu texto, de forma expressa, uma finalidade muito similar, visava a melhoria da eficiência, eficácia e qualidade dos serviços públicos, o desenvolvimento permanente do servidor público, a adequação das competências requeridas dos servidores aos objetivos das instituições e ainda preconizava a divulgação e o gerenciamento das ações de capacitação e a racionalização e efetividade dos gastos com capacitação (BRASIL, 2006a).

$\mathrm{Na}$ esfera federal, em termos de legislação, o debate sobre capacitação de servidores remonta de longa data. Pode-se verificar que o próprio decreto $5.707 / 2006$ revogou outro que versava sobre a mesma temática. No quadro 1 podese acompanhar um pouco desta evolução.

Quadro 1: Evolução histórica de Decretos Presidenciais sobre capacitação de servidores

\begin{tabular}{|l|l|l|}
\hline \multicolumn{1}{|c|}{$\begin{array}{c}\text { Ato } \\
\text { Normativo }\end{array}$} & $\begin{array}{c}\text { Data do } \\
\text { Documento }\end{array}$ & \multicolumn{1}{c|}{ Matéria regulamentada } \\
\hline $\begin{array}{l}\text { Decreto } \mathrm{n}^{\circ} \\
9.991 / 2019\end{array}$ & $28 / 08 / 2019$ & $\begin{array}{l}\text { Dispõe sobre a Política Nacional de Desenvolvimento de } \\
\text { Pessoas da administração pública federal direta, autárquica e } \\
\text { fundacional, e regulamenta dispositivos da Lei } \mathrm{n}^{\circ} \text { 8.112, de 11 } \\
\text { de dezembro de 1990, quanto a licenças e afastamentos para } \\
\text { ações de desenvolvimento. }\end{array}$ \\
\hline $\begin{array}{l}\text { Decreto } \mathrm{n}^{\circ} \\
5.707 / 2006\end{array}$ & $23 / 02 / 2006$ & $\begin{array}{l}\text { Institui a Política e as Diretrizes para o Desenvolvimento de } \\
\text { Pessoal da administração pública federal direta, autárquica e } \\
\text { fundacional, e regulamenta dispositivos da Lei no 8.112, de 11 } \\
\text { de dezembro de 1990. }\end{array}$ \\
\hline $\begin{array}{l}\text { Decreto } \mathrm{n}^{\circ} \\
2.794 / 1998\end{array}$ & $01 / 10 / 1998$ & $\begin{array}{l}\text { Institui a Política Nacional de Capacitação dos Servidores para } \\
\text { a Administração Pública Federal direta, autárquica e } \\
\text { fundacional, e dá outras providências. }\end{array}$ \\
\hline $\begin{array}{l}\text { Decreto } \mathrm{n}^{\circ} \\
2.029 / 1996\end{array}$ & $11 / 10 / 1996$ & $\begin{array}{l}\text { Dispõe sobre a participação de servidores públicos federais em } \\
\text { conferências, congressos, treinamentos ou outros eventos } \\
\text { similares, e dá outras providências. }\end{array}$ \\
\hline $\begin{array}{l}\text { Decreto } \mathrm{n}^{\circ} \\
1.684 / 1995\end{array}$ & $26 / 10 / 1995$ & $\begin{array}{l}\text { Dá nova redação a dispositivos do Decreto no 1.648, de 27 de } \\
\text { setembro de 1995, que dispõe sobre a participação de } \\
\text { servidores públicos federais em conferências, congressos ou } \\
\text { outros eventos similares que se realizarem no País. }\end{array}$ \\
\hline $\begin{array}{l}\text { Decreto } \mathrm{n}^{\circ} \\
1.648 / 1995\end{array}$ & $27 / 09 / 1995$ & $\begin{array}{l}\text { Dispõe sobre a participação de servidores públicos federais em } \\
\text { conferências, congressos ou outros eventos similares, que se } \\
\text { realizarem no País, e dá outras providências. }\end{array}$ \\
\hline $\begin{array}{l}\text { Decreto } \mathrm{n}^{\circ} \\
91.820 / 1985\end{array}$ & $22 / 10 / 1985$ & $\begin{array}{l}\text { Dispõe sobre a dispensa de ponto de servidores públicos } \\
\text { federais para comparecimento a congressos ou reuniões } \\
\text { similares, no País ou no exterior, e dá outras providências. }\end{array}$ \\
\hline $\begin{array}{l}\text { Decreto } \mathrm{n}^{\circ} \\
74.647 / 1974\end{array}$ & $03 / 10 / 1974$ & $\begin{array}{l}\text { Dispõe sobre a dispensa de ponto de servidores públicos } \\
\text { federais para comparecimento a congressos ou reuniões } \\
\text { similares, no país ou no exterior, e da outras providencias. }\end{array}$ \\
\hline
\end{tabular}

Fonte: Adaptado de planalto.gov.br. Disponível em: http://www4.planalto.gov.br/legislacao/, acesso em: 13 set. 2019 
Voltando ao Decreto $n^{\circ} 5.707 / 2006$, objeto de estudo da presente pesquisa, verifica-se, em seu artigo $2^{\circ}$, a apresentação do conceito de capacitação, gestão por competências e eventos de capacitação da seguinte forma:

I - capacitação: processo permanente e deliberado de aprendizagem, com o propósito de contribuir para o desenvolvimento de competências institucionais por meio do desenvolvimento de competências individuais;

II - gestão por competência: gestão da capacitação orientada para o desenvolvimento do conjunto de conhecimentos, habilidades e atitudes necessárias ao desempenho das funções dos servidores, visando ao alcance dos objetivos da instituição; e

III - eventos de capacitação: cursos presenciais e à distância, aprendizagem em serviço, grupos formais de estudos, intercâmbios, estágios, seminários e congressos, que contribuam para o desenvolvimento do servidor e que atendam aos interesses da administração pública federal direta, autárquica e fundacional (BRASIL, 2006a).

As diretrizes daquela PNDP (Decreto $n^{\circ}$ 5.707/2006) estavam dispostas no artigo $3^{\circ}$ e apontavam para 0 incentivo às iniciativas pessoais e oferta de oportunidades de capacitação aos servidores, visando ao desenvolvimento de competências institucionais e individuais. Incentivava a formação gerencial e o estímulo da formação inicial (através de cursos introdutórios aos novos servidores) e formação continuada (através de cursos de aperfeiçoamento ao longo da carreira). Estimulava a inclusão de atividades de capacitação como requisito para promoção funcional e a oportunidade de requalificação dos servidores redistribuídos. Considerava o resultado das ações de capacitação e a mensuração do desempenho do servidor complementares entre si, bem como apontava para a necessidade de avaliação permanente dos resultados das ações de capacitação. Determinava a elaboração do Plano Anual de Capacitação (PAC), ampla divulgação das ações de capacitação e para a necessidade de se priorizar, no caso de eventos externos de aprendizagem, os cursos ofertados pelas escolas de governo (BRASIL, 2006a).

Os instrumentos que compunham a antiga PNDP estavam dispostos no artigo $5^{\circ}$ do Decreto 5.707/2006 e foram disciplinados pela Portaria MPOG n. 208/2006. Eram eles: plano anual de capacitação; relatório de execução do plano anual de capacitação; sistema de gestão por competência.

I - Plano Anual de Capacitação: documento elaborado pelos órgãos e entidades para orientação interna, que compreenderá as definições 
dos temas, as metodologias de capacitação a serem implementadas, bem como as ações de capacitação voltadas à habilitação de seus servidores;

II - Relatório de Execução do Plano Anual de Capacitação: documento elaborado pelos órgãos e entidades contendo as informações sobre as ações de capacitação realizadas no ano anterior e a análise dos resultados alcançados; e

III - Sistema de Gestão por Competência: é a ferramenta gerencial que permite planejar, monitorar e avaliar ações de capacitação a partir da identificação dos conhecimentos, das habilidades e das atitudes necessárias ao desempenho das funções dos servidores (BRASIL, 2006b).

O desenvolvimento e implementação de metodologias do sistema de gestão por competências citada acima era atribuição da Secretaria de Gestão (SEGES) do MPOG e da Secretaria de Recursos Humanos (SRH), também do MPOG (BRASIL, 2006b). Segundo o Guia da Gestão da Capacitação por Competências editado pelo MPOG em 2013, o sistema desenvolvido foi intitulado "Sistema Capacitação" e estaria disponível para todos os órgãos da administração pública que já tivessem finalizada a etapa do mapeamento de suas competências (BRASIL, 2013, p. 16), no IFRS, porém, o mapeamento de competências não foi realizado, bem como não foi implantado ou utilizado o Sistema Capacitação.

\section{PLANEJAMENTO E CONTROLE DAS AÇÕES DE CAPACITAÇÃO}

Em se tratando de planejamento das ações de capacitação, no âmbito do IFRS, o Plano Anual de Capacitação (PAC) e os Relatórios de Capacitação estão previstos e normatizados pelo Programa de Capacitação dos Servidores do IFRS Resolução Consup 114/2014 e ainda seguem os preceitos do Decreto $\mathrm{n}^{\circ}$ 5.707/2006, haja visto a recente revogação do mesmo e a impossibilidade temporal de terem sido feitas as devidas adequações ao Decreto $n^{\circ}$ 9.991/2019, em vigor a partir de 06 de setembro de 2019.

De acordo com o Programa de Capacitação, o PAC do IFRS deve especificar ações ou programas de qualificação ou aperfeiçoamento de curta e média duração, planejadas para determinado exercício e contemplar as necessidades da instituição como um todo, preservando a especificidade de cada unidade organizacional (artigos 10 e 11). Essas ações serão identificadas através do Levantamento das Necessidades de Capacitação (LNC) (artigo 17) (IFRS, 2014). 
Relativamente a esse levantamento, Antonello e Pantoja (2010) utilizam o termo avaliação de necessidades (de capacitação) e apontam para a necessidade de se observar o nível organizacional (estrutura organizacional e as suas estratégias), o nível de análise de tarefas (com base nas tarefas de cada um, são elencadas as competências necessárias e necessidade de aprimorá-las), o nível pessoal (quem deve ser capacitado).

Já, para Castro e Borges-Andrade (2004), o termo utilizado é levantamento das necessidades de treinamento (LNT), mais próximo ao termo utilizado pelo IFRS que é levantamento das necessidades de capacitação. Para eles, o LNT trata-se de um estudo prévio, um diagnóstico em que se analisa o que deve ser abordado, para quem e para que servirá, "enfim, para trazer à tona e tornar mais claros os possíveis caminhos de capacitação nos quais a organização deva investir" (CASTRO; BORGES-ANDRADE, 2004, p. 97).

Ainda, de acordo com os mesmos autores, o processo de levantamento das necessidades de capacitação tem também a finalidade de "tornar os participantes corresponsáveis pelo processo e envolvidos politicamente com seus resultados" (CASTRO; BORGES-ANDRADE, 2004, p. 98).

No IFRS, o LNC é realizado anualmente e em cada campus. Quem conduz esse processo é Comissão de Organização e Acompanhamento (COA), que é composta por um membro da gestão de pessoas, um membro representante da carreira docente (membro da Comissão Permanente de Pessoal Docente - CPPD) e um membro da carreira técnico-administrativo em educação (membro da Comissão Interna de Supervisão do Plano de Carreira dos Técnico- Administrativos em Educação - CIS) (IFRS, 2014).

Esse levantamento obedece duas importantes etapas: a primeira diz respeito à dimensão individual, na qual o servidor aponta, individualmente, o que considera como uma necessidade para sua capacitação; a segunda diz respeito à dimensão coletiva/institucional, em que as equipes de trabalho, coletivamente, apontam suas necessidades de capacitação, numa perspectiva institucional, com base nos seus fazeres e nos objetivos estratégicos e finalidades da instituição (IFRS 2014).

O Programa de Capacitação do IFRS aponta que, após realizado o LNC, a COA de cada campus deve elaborar o Plano Anual de Capacitação (PAC), vinculando-o ao cumprimento das metas e propósitos institucionais constantes nos documentos basilares do Instituto, que são o Estatuto, Regimento Geral, Regimento 
Interno e Regimento Complementar, Plano de Desenvolvimento Institucional (PDI), Projeto Pedagógico Institucional e no Plano Diretor de Tecnologia da Informação (PDTI) (IFRS, 2014).

Cabe à Diretoria de Gestão de Pessoas (DGP) da Reitoria agrupar esses planos e elaborar o Plano Anual de Capacitação de todo o IFRS. Compete-lhe também apoiar os servidores e campi em suas iniciativas de capacitação, bem como desenvolver e executar as ações previstas no PAC geral (IFRS, 2014).

Quanto aos prazos, a Portaria MPOG 208/2006 dispõe que o prazo para elaboração do PAC é o primeiro dia útil do mês de dezembro do ano anterior a sua vigência (BRASIL, 2006b). Para o Programa de Capacitação dos Servidores do IFRS, o prazo final para elaboração e envio do PAC das unidades organizacionais à Reitoria é a segunda quinzena de junho do ano anterior a sua vigência, sendo que a DGP (Reitoria) deverá dar publicidade às ações planejadas, no mesmo prazo da Portaria MPOG 208/2016, ou seja, no mês de dezembro do ano anterior à vigência (IFRS, 2014).

Realizado o planejamento e o desenvolvimento das ações de capacitação, há que se controlar e registrar essas informações através de relatórios. O Programa de Capacitação não cita diretamente o Relatório de Execução do Plano Anual de Capacitação expresso pela Portaria n. 208/2006, dispõe sobre o relatório de todas as ações de capacitação desenvolvidas pela Reitoria e campi, não apenas aquelas constantes no PAC. A elaboração desse relatório é de responsabilidade da área de gestão de pessoas das unidades e da Reitoria (IFRS, 2014). O prazo para envio desse relatório ao Sistema de Pessoal Civil da Administração Federal (SIPEC) era 31 de janeiro do ano posterior ao de vigência, sendo que o prazo para entrega da consolidação dos relatórios recebidos pelo SIPEC ao Comitê Gestor da PNDP instituído pelo Decreto 5.707/2006 era 31 de março (BRASIL, 2006b).

\section{ESCOLAS DE GOVERNO E DESENVOLVIMENTO DE GESTORES}

Além de determinar e disciplinar o planejamento e controle das ações de capacitação, o Decreto $n^{\circ} 5.707 / 2006$ conceituava o que deveria ser entendido por Escolas de Governo, muito embora elas já estivessem previstas no $§ 2^{\circ}$ do artigo 39 da Constituição Federal de 1988 (BRASIL, 1988). O referido decreto entendia Escolas de Governo como aquelas instituições que, incluídas na estrutura da 
administração pública federal direta, autárquica e fundacional, teriam como objetivo a formação e o desenvolvimento de servidores públicos, sendo a Escola Nacional de Administração Pública (ENAP) o seu principal exemplo, a única nominada no documento, a quem era expressamente atribuída a função de membro do comitê gestor e a responsabilidade pela promoção, elaboração e execução de ações de capacitação que visassem a preparação para o exercício de cargos de direção e assessoramento superiores, ou seja, capacitação gerencial (BRASIL, 2006a).

Acompanhando o entendimento do Decreto $n^{\circ} 5.707 / 2006$, o Programa de Capacitação dos Servidores do IFRS, também apresenta preocupação com o desenvolvimento de gestores, de forma que a aponta como uma das linhas de desenvolvimento prioritárias para as ações de capacitação. Esta linha descreve o desenvolvimento gerencial, gestão em áreas estratégicas, planejamento, habilidades interpessoais e liderança como as principais temáticas a serem observadas (IFRS, 2014).

\section{COMITÊ GESTOR}

O Decreto $n^{\circ}$ 5.707/2006 criava ainda um Comitê Gestor da PNDP, composto pela Secretaria de Recursos Humanos (MPOG), que era a coordenadora, Secretaria de Gestão (MPOG) e a ENAP. A este comitê competia: avaliar e estabelecer a forma e o conteúdo dos relatórios anuais de execução do PAC dos órgãos e entidades, orientar os órgãos e entidades na alocação de seus recursos de capacitação, promover a disseminação e zelar pela observância daquela PNDP (BRASIL, 2006a).

\section{TREINAMENTO REGULARMENTE INSTITUÍDO}

O Decreto $\mathrm{n}^{\circ} 5.707 / 2006$ conceituava treinamento regularmente instituído como qualquer ação de capacitação que contribuísse para o desenvolvimento do servidor e que atendesse aos interesses da administração pública, tais como: cursos presenciais e à distância, aprendizagem em serviço, grupos formais de estudos, intercâmbios, estágios, seminários e congressos (BRASIL, 2006a).

No âmbito do IFRS, o Programa de Capacitação de Servidores acompanha este entendimento e possibilita aos servidores oportunidades de participação em ações de capacitação. A instituição entende por treinamento regularmente instituído 
[...] qualquer ação de capacitação inserida em um programa institucional, no interesse do IFRS e voltado para a consecução das metas do Plano de Desenvolvimento Institucional (PDI), do Projeto Pedagógico Institucional (PPI) e do Planejamento Estratégico da instituição (IFRS, 2014, p. 7).

As ações de capacitação, no âmbito do IFRS compreendem ações de qualificação e aperfeiçoamento profissional de curta e média duração (IFRS, 2014).

Ações de qualificação são entendidas como aquelas voltadas para a educação formal e consequentemente, ao aumento do nível de escolaridade dos servidores, são previstas e possibilitadas aos servidores pelo IFRS através de: concessão de bolsa de estudo para ressarcimento de mensalidades em cursos de graduação, especialização, mestrado e doutorado; concessão de horário especial estudante; liberação de até quarenta por cento da carga horária para realização de cursos da educação básica, superior e pós-graduação (lato e stricto sensu) para servidores da carreira técnico-administrativo em educação (TAE); e afastamento integral para qualificação (IFRS, 2014; IFRS, 2015).

Ações de aperfeiçoamento profissional de curta e média duração, entendidas como cursos presenciais e à distância, treinamento em serviço, visitas técnicas, palestras, grupos formais de estudos, intercâmbios, estágios, fóruns, seminários, congressos, etc.) também estão salvaguardadas no Programa de Capacitação dos Servidores do IFRS, sendo a participação do servidor considerada como efetivo exercício (IFRS, 2014), o que também acompanha o Decreto $n^{\circ} 5.707 / 2006$.

O IFRS garante aos servidores a possibilidade de participar de cursos e eventos promovidos pela própria instituição, como também por outras instituições no Brasil ou no exterior. Havendo disponibilidade orçamentária e de acordo com o planejamento de cada unidade organizacional, arca com os custos da participação, observando-se os trâmites administrativos necessários (IFRS, 2014; IFRS, 2017).

\section{AFASTAMENTOS PARA AÇÕES DE EDUCAÇÃO FORMAL}

Estendendo a previsão legal da Lei 8.112/90, quanto aos afastamentos para estudo, o Decreto $n^{\circ} 5.707 / 2006$ previa ainda a possibilidade de afastamento para treinamento regularmente instituído quando o cumprimento da jornada semanal de trabalho ficasse inviável, da seguinte maneira: até vinte e quatro meses, para 
mestrado; até quarenta e oito meses, para doutorado; até doze meses, para pósdoutorado ou especialização; e até seis meses, para estágio (BRASIL, 2006a).

Da mesma forma que em outras ações de capacitação, o Programa de Capacitação de Servidores do IFRS também acompanha o Decreto 5.707/2006, pois, prevê que, no interesse da administração, poderá o servidor "afastar-se do cargo efetivo com a respectiva remuneração, para participar de programas de pósgraduação e estágio relacionado à educação formal" tanto no Brasil como no exterior, ficando o afastamento condicionado a "à exoneração do cargo em comissão ou função de direção, chefia e assessoramento superiores, cargo de direção, função gratificada e gratificação de representação" (IFRS, 2014, p. 14). Na instituição há normativas específicas que complementam a regulamentação desta ação de capacitação tanto para a carreira docente, como para a carreira dos técnicoadministrativos em educação (IFRS, 2018c; IFRS, 2016).

\section{LICENÇA CAPACITAÇÃO}

Com relação à Licença para Capacitação, em complementação à Lei 8.112/90, o Decreto $n^{\circ} 5.707 / 2006$ previa que após cada quinquênio de efetivo exercício, estaria facultado ao servidor solicitar ao dirigente máximo do órgão ou entidade de exercício, licença remunerada de até três meses para participar de ação de capacitação, podendo a mesma ser parcelada, desde que a menor parcela não fosse inferior a trinta dias e que fosse respeitado o planejamento interno, a oportunidade e relevância do curso para a instituição, ou seja, que a concessão da licença não prejudicasse as atividades desenvolvidas na unidade organizacional e que os cursos pretendidos tivessem relação com as atribuições do servidor. Havendo possibilidade, a realização do curso ainda poderia ser custeada pela instituição. Poderia também ser utilizada integralmente para a elaboração de dissertação de mestrado ou tese de doutorado, cujo objeto fosse compatível com o plano anual de capacitação da instituição, bem como para realização de atividade voluntária (BRASIL, 2006a).

O programa de capacitação dos servidores do IFRS acompanha este entendimento, indo um pouco além, pois determina que a Licença para Capacitação pode ser concedida para 
[...] realização de estágio não remunerado, cursos de educação a distância, elaboração do relatório de aperfeiçoamento, dos trabalhos de conclusão de graduação e especialização, da dissertação de mestrado, da tese de doutorado e do relatório de pós-doutorado (IFRS, 2014, P. 16).

Acompanha também o referido decreto ao citar que a para a concessão da licença capacitação deve-se observar "planejamento interno de cada unidade organizacional, à oportunidade do afastamento e à relevância do curso para a instituição", podendo a mesma ser parcelada, porém a menor parcela não poder ser inferior a trinta dias, pode também custear a participação do servidor no curso ou evento (caso haja disponibilidade orçamentária e planejamento para isso), estabelece os critérios de preferência, caso não seja possível, ao mesmo tempo, contemplar dois ou mais servidores de uma mesma equipe de trabalho (IFRS, 2014, p. 11).

\section{DEBATE SOBRE DESENVOLVIMENTO DE COMPETÊNCIAS}

Após essa breve explanação do que previa o Decreto $n^{\circ}$ 5.707/2006 e dos desdobramentos dele no Programa de Capacitação dos Servidores do IFRS quanto ao planejamento, controle e ações de capacitação, parece oportuno trazer ao debate a questão da capacitação de servidores orientada pelo desenvolvimento de competências, tendo em vista que este entendimento permanece na Nova PNDP (Decreto 9.991/2019).

O Decreto 5.707/2006 trazia como conceito de capacitação o "processo permanente e deliberado de aprendizagem, com o propósito de contribuir para o desenvolvimento de competências institucionais por meio do desenvolvimento de competências individuais" (BRASIL, 2006a). Ou seja, segundo ele, competências são desenvolvidas por meio de processos contínuos de aprendizagem e são possíveis de ser identificadas no desempenho do indivíduo no trabalho.

Conceituava competência como "conjunto de conhecimentos, habilidades e atitudes necessárias ao desempenho das funções dos servidores, visando ao alcance dos objetivos da instituição" (BRASIL, 2006a).

O programa de capacitação do IFRS acompanha em parte o conceito de capacitação proposto pelo Decreto $n^{\circ} 5.707 / 2006$. Confusamente, ao longo do documento apresenta-se mais do que um conceito de capacitação. O primeiro 
conceito de capacitação apresentado no documento (art. $1^{\circ}$, caput) dita que capacitação deve ser entendida como "um processo de aprendizagem em que fica explícito 'para que', 'como', 'para quem' e 'quando' fazer algo”, englobando, “ação e reflexão de forma sistêmica, e não como meras ações isoladas e fragmentadas" (IFRS, 2014, p. 4). Nesta parte do documento o conceito de capacitação parece se afastar do decreto, porém, logo na sequência (parágrafo único do art. $1^{\circ}$ ), aponta que "capacitação desenvolve competências, que são resultados de conhecimentos, habilidades e atitudes construídos institucionalmente quando desenvolvido nos indivíduos que compõem o corpo de servidores" (IFRS, 2014, p. 4), aproximando-se novamente do decreto.

Ainda na perspectiva da aproximação ao decreto, um novo conceito se apresenta no documento (art. $9^{\circ}$ ), entendendo-se por capacitação o

[...] processo permanente e deliberado de aprendizagem, que utiliza ações de aperfeiçoamento e de qualificação, através de eventos de capacitação, com o propósito de contribuir para o desenvolvimento de competências institucionais, por meio do aprimoramento de competências individuais (IFRS, 2014, p. 7)

O Programa de Capacitação dos Servidores do IFRS acompanha também o Decreto 5.707/2006 ao preconizar que se constitui em uma "ferramenta da gestão de pessoas em busca da eficiência, eficácia e qualidade dos serviços prestados à sociedade em consonância com [...] os interesses institucionais", por meio do desenvolvimento de "competências individuais e institucionais" (IFRS, 2014, p. 4).

$\mathrm{Na}$ perspectiva das Ciências Sociais Aplicadas, na área da Administração, o conceito de competência, para Fleury (2002, p. 55), refere-se a um "saber agir responsável e reconhecido que implica mobilizar, integrar, transferir conhecimentos, recursos, habilidades, que agregue valor econômico à organização e valor social ao indivíduo".

Brandão e Guimarães (2001, p. 10), apoiados em Durand (1998), apontam que o conceito de competência pressupõe, além de questões técnicas, a cognição e atitudes relacionadas ao trabalho. Conceituam, assim, competência como "conjunto de conhecimentos, habilidades e atitudes necessários à consecução de determinado propósito". 
De Mello e Amâncio Filho (2010) apontam que é por meio dos processos de aprendizagem permanente e gestão do conhecimento que as instituições podem desenvolver competências.

Na literatura da área da administração percebe-se a distinção entre o conceito de competências essenciais, organizacionais e competências individuais.

Competências essenciais são aquelas que diferenciam uma organização ou instituição da outra, são o seu diferencial perante outras organizações ou instituições e isso é percebido pelas pessoas. Competências organizacionais, por sua vez, são aquelas necessárias para o desenvolvimento de cada função da organização ou instituição (FLEURY; FLEURY, 2004).

Na antiga PNDP (Decreto 5.707/2006), as competências organizacionais ou essenciais estavam expressas pelo nome de competências institucionais (BRASIL, 2006a).

Porém não há que se falar de desenvolvimento de competências essenciais ou organizacionais sem considerar o desenvolvimento de competências individuais e o contexto institucional. O desafio da área de gestão de pessoas, nesse aspecto, é o de alinhar as competências individuais com as organizacionais, garantindo que, no processo de desenvolvimento de competências, agregue-se valor ao indivíduo e a busca pelo atingimento dos objetivos estratégicos da organização (FLEURY; FLEURY, 2004).

Do exposto, percebe-se que o Decreto n. 5.707/2006, ao conceituar capacitação como "processo permanente e deliberado de aprendizagem, com o propósito de contribuir para o desenvolvimento de competências institucionais por meio do desenvolvimento de competências individuais" e gestão por competências como a "gestão da capacitação orientada para o desenvolvimento do conjunto de conhecimentos, habilidades e atitudes necessárias ao desempenho das funções dos servidores, visando ao alcance dos objetivos da instituição" (BRASIL, 2006a), alinhase com as proposições da área da administração de que para o sucesso organizacional faz-se necessário contar com profissionais amplamente preparados, capacitados para o desenvolvimento de suas funções e que as auxiliem na busca dos resultados estratégicos esperados.

Porém, sem sair da área da Administração, autores como Antonello e Pantoja (2010) e Brandão e Guimarães (2001) fazem críticas à forma como a gestão de competências deve ser adotada nas organizações. 
Quanto ao Decreto $\mathrm{n}^{\circ}$ 5.707/2006, na esfera dos servidores federais, Antonello e Pantoja (2010) apontam que "lacunas" ou falhas de desempenho nem sempre têm sua origem em inabilidade ou falta de conhecimento. Outros fatores influenciam esse fenômeno. Questões que envolvem gerenciamento inadequado das condições e do ambiente de trabalho influenciam no desempenho profissional e não serão desenvolvidas com capacitação, pois, muitas vezes, as pessoas já possuem as competências necessárias para uma determinada atividade, mas não têm a oportunidade de colocá-las em prática (ANTONELLO; PANTOJA, 2010).

Para Brandão e Guimarães (2001), o desenvolvimento das pessoas deve ser visto de forma ampla, proporcionando crescimento e autonomia. Do contrário, poderão se configurar como mais uma forma de controle social de trabalhadores e manutenção das estruturas de poder nas organizações.

Brandão e Guimarães (2001) alertam para os processos de objetivação e individualização do trabalho. Para eles, a objetivação do trabalho ocorre quando, numa perspectiva quantitativa, procura-se estimar o valor da contribuição do trabalhador para o atingimento dos objetivos organizacionais. A individualização reforça o individualismo como estratégia para evitar a mobilização dos trabalhadores em prol de reivindicações coletivas.

Ainda de acordo com Brandão e Guimarães (2001), a gestão por competências deve preparar o trabalhador para o trabalho de forma integral, auxiliando a instituição da qual faz parte a atingir suas finalidades de objetivos, gerando valor social ao indivíduo e valor econômico para a organização.

Outra crítica ao modelo de gestão por competência trazido pelo Decreto $\mathrm{n}^{\circ}$ 5.707/2006 reside no fato de que competência pressupõe uma ação. O ato de conhecer (conhecimento) não desenvolve competência sozinho. Precisa ser posto em prática através de uma ação, e o ato de agir tem várias motivações. Motivação não ocorre em cursos de natureza comportamental, envolve muito mais do que isso, envolve fatores econômicos, políticos, de acesso a bens e serviços, de segurança, que extrapolam a esfera pessoal e organizacional. Assim, a aprendizagem proporcionada por cursos de capacitação, por si só, não desenvolve competência, pois essa se concretiza com um agir de forma consciente, mobilizando conhecimentos tácitos e científicos para solução de situações não previstas. (KUENZER, 2002; KUENZER, 2004). 
De acordo com Kuenzer (2002, p. 5), "conhecimentos e competências são processos que se articulam, mas não se identificam", pois a simples existência de conhecimentos, sejam tácitos ou teóricos, não é suficiente para desencadear ações competentes.

Kuenzer (2002, p. 7) conceitua competência como

[...] a capacidade de agir, em situações previstas e não previstas, com rapidez e eficiência, articulando conhecimentos tácitos e científicos a experiências de vida e laborais vivenciadas ao longo das histórias de vida. Esta concepção de competência vincula-se a ideia de solucionar problemas, mobilizando conhecimentos de forma transdisciplinar a comportamentos e habilidades psicofísicas, e transferindo-os para novas situações; supõe, portanto, a capacidade de atuar mobilizando conhecimentos.

Para Chinelli, Vieira e Deluiz (2013, p. 36), o conceito de competência está atrelado à teoria do capital humano, e juntos constituem a "base ideológica do capitalismo contemporâneo". Apontam para a impossibilidade de o conceito de competências orientar propostas de formação profissional que atendam aos interesses dos trabalhadores, "pois ele impediria a construção do princípio da formação humana em uma perspectiva contra-hegemônica" que só pode ser construída numa perspectiva histórico-crítica, resgatando-se o trabalho como princípio educativo (CHINELLI; VIEIRA; DELUIZ, 2013, p. 37).

As mesmas autoras ainda enfatizam a impossibilidade de adoção do modelo de competência em instituições que não tenham natureza econômica, a exemplo da área de serviços em saúde (CHINELLI; VIEIRA; DELUIZ, 2013), o que por analogia, pode ser aplicado também à área da educação profissional e tecnológica.

Para Ramos (2003), a noção de competências, tem por finalidade a adaptação do trabalhador ao meio (mercado), conhecimento da parte e não da totalidade. No mesmo sentido Kuenzer (2016) aponta que a formação de trabalhadores com foco no desenvolvimento de competências visa a formação de trabalhadores flexíveis, através de conhecimentos fragmentados, dando-se mais ênfase à adaptabilidade do que ao conhecimento, combinações estas que ora incluem e ora excluem trabalhadores.

Assim, entende-se que as ações de capacitação de servidores do IFRS, profissionais que resguardadas as devidas atribuições, são educadores que tem por 
missão a formação humana integral de cidadãos, não deve pautar-se na adoção de um modelo de competências que vise o conhecimento fragmentado, pelo contrário, devem ser orientadas pelo conceito de competência que articula teoria e prática, parte e totalidade, o pensar e o fazer, proposto por Kuenzer (2002), visando a omnilateralidade. O que, de certa forma, está em conformidade com o primeiro conceito de capacitação trazido pelo programa de capacitação dos servidores do IFRS (caput do art. $1^{\circ}$ ), "um processo de aprendizagem em que fica explícito 'para que', 'como', 'para quem' e 'quando' fazer algo", englobando, “ação e reflexão de forma sistêmica, e não como meras ações isoladas e fragmentadas" (IFRS, 2014, p. 4).

\section{CONSIDERAÇÕES FINAIS}

O texto apresentado procurou apresentar um panorama do então revogado Decreto $n^{\circ} 5.707 / 2006$, com relação às suas disposições, traçando um paralelo com - Programa de Capacitação de Servidores do IFRS (Resolução Consup IFRS 114/2014), para futuramente embasar um novo estudo relativo aos impactos do Decreto $n^{\circ}$ 9.991/2016, vigente a partir de 06 de setembro de 2019.

De maneira geral, o Programa de Capacitação dos Servidores do IFRS acompanha ao que preconizava o Decreto $n^{\circ} 5.707 / 2006$, e em alguns momentos propõe avanços perante as suas disposições.

Por mais que não seja esse o objetivo do presente artigo, já é possível concluir que um dos impactos da Nova PNDP (Decreto n 9.991/2019) será a revisão do Programa de Capacitação dos Servidores do IFRS, bem como das demais normativas internas que regem o tema no âmbito do IFRS.

Alerta-se, porém, que ao revisar estes documentos, não se tenha a perspectiva da formação fragmentada dos servidores, voltada para conformação de competências flexíveis, que deem mais ênfase à adaptabilidade do que ao conhecimento propriamente dito. Que adote-se práticas e políticas de desenvolvimento de servidores que assegurem a formação humana integral, que, além do horizonte de transformação da realidade, de forma a garantir a oferta de ensino, pesquisa e extensão, gratuitos e de qualidade à comunidade no qual se insere, proporcione ao servidor os elementos necessários para compreender as especificidades de uma instituição de EPT, qualquer que seja a sua atuação. 


\section{REFERÊNCIAS}

ANTONELLO, C. S.; PANTOJA, M. J. In: CAMÕES, M. R. de S.; PANTOJA, M. J.; BERGUE, S. T. Org. Gestão de pessoas: bases teóricas e experiências no setor público. 2010, p. 51-101. Brasília: ENAP, 2010.

BRANDÃO, H. P.; GUIMARÃES, T. A. Gestão de competências e gestão de desempenho: tecnologias distintas ou instrumentos de um mesmo construto? Revista de Administração de empresas, v. 41, n. 1, p. 8-15, 2001.Disponível em: http://www.scielo.br/pdf/rae/v41n1/v41n1a02.pdf. Acesso em: 18 abr. 2019

BRASIL. Constituição da República Federativa do Brasil. Brasília: 1988. Disponível em: http://www.planalto.gov.br/ccivil_03/Constituicao/Constituicao.htm. Acesso em: 02 set. 2019.

Decreto 5.707, de 23 de fevereiro de 2006. Institui a Política e as Diretrizes para o Desenvolvimento de Pessoal da administração pública federal direta, autárquica e fundacional, e regulamenta dispositivos da Lei no 8.112, de 11 de dezembro de 1990. Brasília: 2006a Disponível em: http://www.planalto.gov.br/ccivil_03/_Ato2004-2006/2006/Decreto/D5707.htm. Acesso em: 18 dez. 2018

. Decreto 9.991, de 28 de agosto de 2019. Dispõe sobre a Política Nacional de Desenvolvimento de Pessoas da administração pública federal direta, autárquica e fundacional, e regulamenta dispositivos da Lei $n^{\circ} 8.112$, de 11 de dezembro de 1990, quanto a licenças e afastamentos para ações de desenvolvimento. Brasília: 2019b. Disponível em: http://www.planalto.gov.br/ccivil_03/_ato20192022/2019/decreto/D9991.htm. Acesso em: 02 set. 2019.

Decreto 2.794 , de $1^{\circ}$ de outubro de 1998. Institui a Política Nacional de Capacitação dos Servidores para a Administração Pública Federal direta, autárquica e fundacional, e dá outras providências. Brasília: 1998. Disponível em: http://www.planalto.gov.br/ccivil_03/decreto/D2794.htm. Acesso em: 13 set. 2019.

Decreto 2.029, de 11 de outubro de 1996. Dispõe sobre a participação de servidores públicos federais em conferências, congressos, treinamentos ou outros eventos similares, e dá outras providências. Brasília: 1996. Disponível em: http://www.planalto.gov.br/ccivil_03/decreto/D2029.htm. Acesso em: 13 set. 2019.

Decreto 1.684, de 26 de outubro de 1995. Dá nova redação a dispositivos do Decreto $n^{\circ} 1.648$, de 27 de setembro de 1995, que dispõe sobre a participação de servidores públicos federais em conferências, congressos ou outros eventos similares que se realizarem no País. Brasília: 1995. Disponível em: http://www.planalto.gov.br/ccivil_03/decreto/1995/d1684.htm. Acesso em: 13 set. 2019.

Decreto 1.648, de 27 de setembro de 1995. Dispõe sobre a participação de servidores públicos federais em conferências, congressos ou outros eventos similares, que se realizarem no País, e dá outras providências. Brasília: 1995. 
Disponível em: http://www.planalto.gov.br/ccivil_03/decreto/1995/D1648.htm. Acesso em: 13 set. 2019.

Decreto 91.820, de 22 de outubro de 1985. Dispõe sobre a dispensa de ponto de servidores públicos federais para comparecimento a congressos ou reuniões similares, no País ou no exterior, e dá outras providências. Brasília: 1985. Disponível em: http://www.planalto.gov.br/ccivil_03/Atos/decretos/1985/D91820.html. Acesso em: 13 set. 2019.

Decreto 74.647, de 03 de outubro de 1974. Dispõe sobre a dispensa de ponto de servidores públicos federais para comparecimento a congressos ou reuniões similares, no País ou no exterior, e dá outras providências. Brasília: 1974. Disponível em: http://legis.senado.leg.br/norma/497287/publicacao/15670861. Acesso em: 13 set. 2019.

Lei 11.892 de 29 de dezembro de 2008. Institui a Rede Federal de Educação Profissional, Científica e Tecnológica, cria os Institutos Federais de Educação, Ciência e Tecnologia, e dá outras providências. Brasília: 2008. Disponível em: http://www.planalto.gov.br/ccivil_03/_ato2007-2010/2008/lei//11892.htm. Acesso em 01 dez. 2018.

. MINISTÉRIO DA ECONOMIA. Secretaria Especial de Desburocratização, Gestão e Governo Digital/Secretaria de Gestão e Desempenho de Pessoal. Instrução Normativa n $^{\circ}$ 201, de 11 de setembro de 2019. Brasília: 2019c. Disponível em: http://www.in.gov.br/en/web/dou/-/instrucao-normativa-n-201-de-11de-setembro-de-2019-215812638. Acesso em: 13 set. 2019.

. MINISTÉRIO DA EDUCAÇÃO. Um novo modelo de Educação Profissional e Tecnológica. Concepções e Diretrizes. 2010. Disponível em: http://portal.mec.gov.br/index.php?option=com_docman\&view=download\&alias=6691 -if-concepcaoediretrizes\&category_slug=setembro-2010-pdf\&Itemid=30192. Acesso em 02 dez. 2018.

. MINISTÉRIO DA EDUCAÇÃO. Plataforma Nilo Peçanha. Brasília: 2019a. Disponível em: http://plataformanilopecanha.mec.gov.br/. Acesso em 08 abr. 2019.

. MINISTÉRIO DO PLANEJAMENTO ORÇAMENTO E GESTÃO. Portaria 208, de 25 de julho de 2006. Brasília: 2006b.Disponível em:

https://conlegis.planejamento.gov.br/conlegis/legislacao/atoNormativoDetalhesPub.ht m?id=2576. Acesso em 11 dez. 2018

. MINISTÉRIO DO PLANEJAMENTO, ORÇAMENTO E GESTÃO. Secretaria de Gestão Pública. Guia para gestão de capacitação por competências. Brasília, DF, 2013. Disponível em: http://www.gespublica.gov.br/content/guia-dagest \%C3\%A3o-da-capacita\%C3\%A7\%C3\%A3o-por-compet\%C3\%AAncias; Acesso em: 28n maio. 2019.

CASTRO, P. M. R. de; BORGES-ANDRADE, J. E. Identificação das necessidades de capacitação profissional: o caso dos assistentes administrativos da Universidade de Brasília. Revista de Administração da USP, v. 39, n. 1, p. 96-108, 2004. 
Disponível em:

https://s3.amazonaws.com/academia.edu.documents/33278125/artigo_atitude_habi lidade_e_conhecimento.pdf?AWSAccessKeyld=AKIAIWOWYYGZ2Y53̈UL3A\&Expire $s=155 \overline{8} 0 \overline{3} 2232 \&$ Signature $=P n \% 2 B 8 j m m v K T 2 y d C R N V D 9 w B C R 6 p K k \% 3 D \&$ response -contentdisposition=inline $\% 3 \mathrm{~B} \% 20$ filename\%3DIdentificacao_das_necessidades_de_capaci. pdf. Acesso em 16 maio. 2019.

CHINELLI, F.; VIEIRA, M.; DELUIZ, N. O Conceito de Qualificação e a Formação para o Trabalho em Saúde. In: MOROSINI, Márcia Valéria Guimarães Cardoso et al (Org.). Trabalhadores Técnicos em Saúde: aspectos da qualificação profissional no SUS. Rio de Janeiro: Epsjv, 2013. p. 23-48. Disponível em: <https://www.arca.fiocruz.br/bitstream/icict/8650/2/Livro\%20EPSJV\%20012382.pdf>. Acesso em: 17 jun. 2019.

DE MELLO, M. L. B. C.; AMÂNCIO FILHO, A. A gestão de recursos humanos em uma instituição pública brasileira de ciência e tecnologia em saúde: o caso Fiocruz. Revista de Administração Pública, v. 44, n. 3, p. 613-636, 2010. Disponível em: http://bibliotecadigital.fgv.br/ojs/index.php/rap/article/view/6939. Acesso em: 25 abr. 2019.

FLEURY, M. T. L. A gestão de competências e a estratégia organizacional. In: As pessoas na organização. 11. ed. São Paulo: Editora Gente, 2002. p. $51-61$.

FLEURY, M.T. L; FLEURY, A. C. C. Alinhando estratégia e competências. Revista de administração de empresas, v. 44, n. 1, p. 44-57, 2004. Disponível em: http://www.scielo.br/scielo.php?pid=S003475902004000100012\&script=sci_arttext\&tlng=pt. Acesso em: 18 abr. 2019

GIL, A. C. Como elaborar projetos de pesquisa. São Paulo: Atlas, 2002.

IFRS. Instituto Federal de Educação, Ciência e Tecnologia do Rio Grande do Sul. Bento Gonçalves: 2018a. Disponível em: https://ifrs.edu.br/. Acesso em: 02 dez. 2018.

. Conselho Superior. Resolução n 114/2014, de 16 de dezembro de 2014. Programa de Capacitação dos Servidores do IFRS. Bento Gonçalves: Conselho Superior, 2014. Disponível em: https://ifrs.edu.br/documentos/resolucao-consup-no114-de-16-de-dezembro-de-2014-programa-de-capacitacao-dos-servidores-do-ifrs/. Acesso em: 16 maio. 2019

. Conselho Superior. Resolução n 080/2016, de 13 de dezembro de 2016. Regulamento de Afastamento dos Servidores Técnico-Administrativos em Educação do Instituto Federal do Rio Grande do Sul. Bento Gonçalves: Conselho Superior, 2016. Disponível em: https://ifrs.edu.br/wpcontent/uploads/2017/08/Resolu\%C3\%A7\%C3\%A3o-080.pdf. Acesso em: 13 set. 2019. 
. Conselho Superior. Resolução n 84/2018, de 11 de dezembro de 2018.

Plano de Desenvolvimento Institucional 2019-2023 do Instituto Federal do Rio Grande do Sul (PDI). Bento Gonçalves: Conselho Superior, 2018b. Disponível em: https://ifrs.edu.br/wpcontent/uploads/2019/01/Resolucao_084_18_Aprova_PDI_2019_2023_Completa.pd f Acesso em: 08 jan. 2019.

Gabinete do Reitor. Instrução Normativa $n^{\circ}$ 06, de 11 de maio de 2015. Regulamenta o artigo 36 da Resolução Consup n 114/2014 que instituiu a Liberação de Carga Horária aos servidores Técnico-Administrativos no âmbito do IFRS. Bento Gonçalves: 2015. Disponível em: https://ifrs.edu.br/wp-content/uploads/2017/08/ln-006-2017Libera\%C3\%A7\%C3\%A3o-Carga-Hor\%C3\%A1ria-TAE-publica\%C3\%A7\%C3\%A3ono-site.pdf. Acesso em: 13 set. 2019.

. Gabinete do Reitor. Instrução Normativa n 08, de 08 de maio de 2017. Regulamenta os fluxos e processos para pedidos de participação dos servidores do IFRS em ações de capacitação de curta duração realizadas no país. Bento Gonçalves: 2017. Disponível em: https://ifrs.edu.br/wp-content/uploads/2017/08/IN08-2017-Pedidos-de-Capacitacao-no-Pais.pdf. Acesso em: 13 set. 2019.

. Gabinete do Reitor. Instrução Normativa n 02, de 24 de agosto de 2018. Regulamenta os critérios de afastamento de servidores docentes para capacitação/qualificação em programas de pós-graduação. Bento Gonçalves: 2018c. Disponível em: https://ifrs.edu.br/wp-content/uploads/2018/09/IN-02-2018AFASTAMENTO-DOCENTE-1-2.pdf. Acesso em: 13 set. 2019.

KUENZER, A. Z. Conhecimento e Competências no Trabalho e na Escola. Boletim Técnico do Senac, v. 28, n. 2, p. 02-11, maio/ago. 2002. Disponível em: http://www.bts.senac.br/index.php/bts/issue/view/62/showToc. Acesso em 28 nov. 2018.

. Competência como práxis: os dilemas da relação entre teoria e prática na educação dos trabalhadores. Boletim técnico do SENAC, v. 30, n. 3, p. 81-93, set/dez, 2004. Disponível em: http://bts.senac.br/index.php/bts/article/view/501. Acesso em: 05 mar 2019.

. A formação dos trabalhadores no espaço de trabalho. Trabalho Necessário, Niterói, v. 14, n. 25, p.37-52, 2016. Disponível em: https://doi.org/10.22409/tn.14i25.p9620. Acesso em: 03 jul. 2019.

NEGRINE, A. Instrumentos de coleta de informações na pesquisa qualitativa. In: NETO, V. M.; TRIVIÑOS, A. N. S. (Org.). A pesquisa qualitativa na educação física: alternativas metodológicas. Porto Alegre: Sulina, 2010.

RAMOS. M. N. É possível uma pedagogia das competências contra-hegemônica?: relações entre pedagogia das competências, construtivismo e neopragmatismo. Trabalho, Educação e Saúde., Rio de Janeiro, v. 1, n. 1, p.93114, 2003. Disponível em: <http://www.scielo.br/scielo.php?pid=S198177462003000100008\&script=sci_abstract\&tlng=pt>. Acesso em: 04 jul. 2019. 
SILVEIRA, D. T.; CÓRDOVA, F. P. A pesquisa científica. In: GERHARDT, T. E; SILVEIRA, D. T. Métodos de Pesquisa. Porto Alegre: Editora da UFRGS, 2009, p. $31-42$. 